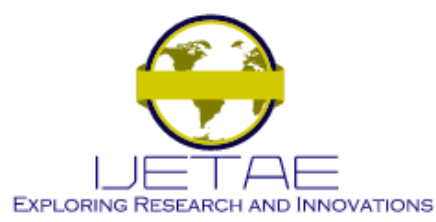

International Journal of Emerging Technology and Advanced Engineering Website: www.ijetae.com (ISSN 2250-2459, Volume 2, Issue 9, September 2012)

\title{
Power Quality Issues and Need of Intelligent PQ Monitoring in the Smart Grid Environment
}

\author{
S. H. Laskar ${ }^{1}$, Mohibullah ${ }^{2}$ \\ ${ }^{I}$ Department of Electronics \& Instrumentation Engg, NIT, Silchar-788010 (India) \\ ${ }^{2}$ Dept of Electrical Engg, Zakir Hussain of College of Engg \& Tech., AMU, Aligarh (India)
}

\begin{abstract}
PQ issues are very much important for utilities, customers and end users and it is essential to be known by the concerned authorities and users for reduction of economic losses due to the poor $P Q$. The cost of poor $P Q$ is high and rising. The paper gives insights on global economical losses due to poor $P Q$. The business risk posed by $P Q$ problems is a real one with even 'low tech' industries exposed to serious financial losses. The global economic meltdown is not the only factor that is pulling down the revenues of Asian countries. A study released said Indian industries lost more than \$ 9.6 billion in 2008-09 due to power outages. According to 2008 reports, poor power quality costs European business more than 150 billion dollars a year. In this paper, a comprehensive survey on different power quality related problems as experienced by customers in different countries are highlighted. Summary of $P Q$ costs are given. As the consequence of poor $P Q$ might have large financial impacts on a country's economy, more initiatives are expected from the concerned parties and regulating bodies to take corrective measures for maintaining better power quality from utility and at end users. Smart grid requires intelligent PQ monitoring to solve different PQ related problems. Authors proposed an intelligent power quality monitoring system that will help to detect different $P Q$ disturbances and consequently assist in employing or implementing appropriate mitigation techniques.
\end{abstract}

Keywords - Deregulation, harmonics, interruptions, Power quality, voltage sag, smart grid, power quality monitoring.

\section{INTRODUCTION}

Electric power quality $(\mathrm{PQ})$ has become the concern of utilities, end users, manufacturers, and all other customers. Power quality is the set of parameters defining the properties of power supply delivered to the users in normal operating conditions in terms of continuity of supply and characteristics of voltage (magnitude, frequency, symmetry, waveform etc.). Modern electronic equipments and devices, such as microprocessors, microcontrollers, tele communications equipment and sensitive computerized equ ipments etc. are susceptible to PQ problems. Poor PQ has become a more important concern of both power suppliers and customers.
Application of deregulation policy in power systems results in growing attention regarding power quality issues. Although much efforts and investments are done by utilities to prevent power interruptions, it is not possible to completely control disturbances on the supply system. Many disturbances are due to normal operations such as switching loads and capacitors or faults and opening of circuit breakers to clear faults. Faults are usually caused by events outside the utility's control. These events include acts of nature such as lightning, birds flying close to power lines and getting electrocuted, and accidental acts such as trees or equipment contacting power lines[1],[2].

A large number of disturbances generated by customerowned equipments and plant operations are beyond the utility's control. In industrial and commercial facilities, disturbances may be caused by the operation of arc welders and the switching of power factor capacitors and inductive loads such as motors, transformers, and lighting ballast solenoids. Moreover, fluorescent lamps, CFLs, and other devices that use power electronics such as switch-mode power supplies, television sets, light dimmers, and adjustable-speed drives can also inject harmonics into the power system [3]. Hence reliable power is essential for both utilities and customers.

Although power production continues to keep up with demand, investments in transmission assets have been in a steady decline for many years, steadily undermining the grids reliability. Consequently, any drop in supply reliability is surely going to impact power quality. The aging power grid infrastructure and the incompatibility between present load characteristics and the electric power supply environment frequently give rise to poor power quality. This results in significant economic losses in a wide range of industries, including financial, services, health care, high tech, and process manufacturing. A decrease in supply voltage for a fraction of a second can trip a microprocessor-based controller offline, disrupting an entire manufacturing process. The cost of a $\mathrm{kWh}$ not supplied because of an outage is much higher than the cost of a $\mathrm{kWh}$ that is supplied when needed [4]. 


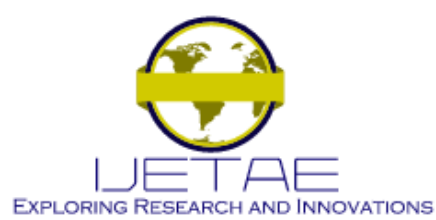

\section{International Journal of Emerging Technology and Advanced Engineering Website: www.ijetae.com (ISSN 2250-2459, Volume 2, Issue 9, September 2012)}

The global bill for poor power quality is more than 500 billion Euros per year which is $50 \%$ of the turnover of the global electricity sector. For many business uses, the cost of poor PQ is higher than the electricity bill and the cost is rising. Also it has been observed in $[5,6]$ that utility deregulation effects on power quality requiring industrywide action to maintain sufficient standards

One of the most critical issues in ensuring reliability is monitoring power system performance [5]. Monitoring can provide information about power flow and demand and help identify the cause of power system disturbances. It can even help identify problem conditions on a power system before they cause interruptions or disturbances. Many systems are affected due to absence of an effective PQM programme.

A solution for this problem is to design a system basing on IEEE recommended practice [3, 10], suitable for exact power quality measurement and monitoring, so that necessary steps may be taken as precautions/and for proper controlling. Although much works are done on Real-Time Power Quality Monitoring, still much improvement is required for present day problems. We are in need of an intelligent system with up-to-date and appropriate software that works smoothly with appropriate hardware to form a compact single station/system for power quality monitoring and controlling without the use of different devices from different vendors. PQM method should replace earlier methods of one way communication. This should be compatible with smart grid sensors for smart metering with advanced metering infrastructure (AMI) in distribution system (two-way communication).

\section{POWER QuALITY IsSUES AND DISTURBANCES}

Defining power quality and its disturbances is one of the $\mathrm{PQ}$ issues [1],[2],[5]. An overview of PQ definitions will be helpful in understanding different $P Q$ events or parameters. In a broad sense power quality may be defined as "any power problem manifested in voltage, current, or frequency deviations that result in failure or disoperation of customer equipment" [3].

"High Power Quality" has become one of the aims of industrial systems design due to the widespread use of electronic based equipments in nearly every aspect of our modern life. The most significant power quality problems that are responsible for poor power quality and are having detrimental effect on industrial load operation are voltage sags, supply interruptions, harmonics and voltage flickers [3], [6]. Thus electric power quality has become an important issue in the deregulated power systems.
Deregulation is resulting in important structure changes in the utility industry and presents the possibility of improving the system operation efficiency. However, there are some significant impacts of deregulation on power quality which need improved mitigation [6].

\section{A. Voltage Sag}

Dips or sags are short-term reductions in the RMS value of supply voltage lasting from a fraction of a second up to several seconds. A sudden reduction (between 10\% and $90 \%$ ) of the voltage magnitude at a point in the electric system and lasting from 0.5 cycles to few seconds is termed as Voltage sag. A voltage dip can be caused either by switching operations or any type of faults as well as fault clearing process. Switching like those associated with a temporary disconnection of the supply or flow of heavy currents associated with the starting of large motor loads is the most common. These events maybe originated at the utility side or at the customer site.

In a deregulated environment, a suitable counter measure is required to be taken to prevent system from deterioration; otherwise probability of increase in the number of the voltage sag events is more.

\section{B. Interruption}

A very short but complete loss of supply is called an interruption. An interruption occurs when the supply voltage decrease less than $10 \%$ from its original value up to a period of time not exceeding one minute. The number of interruptions of the supply also tends to increase in deregulated environment like voltage sags and a suitable mitigation is essential.

\section{Harmonics}

A sinusoidal component of a periodic waveform having a frequency that is an integral multiple of the fundamental system frequency [1], [3]. The Nonlinear characteristics of devices and loads on the power system give rise to harmonic distortion. Harmonic distortion levels are described by the complete harmonic spectrum with magnitudes and phase angle of each harmonic component. Despite its deficiency as in [1], [2] the Total Harmonic Distortion THD is frequently used as a measure of the degree of harmonic distortion of the system. In a deregulated environment harmonic problems will continue to increase because of the fact that the independent power producers IPP, which are using wind and solar energy to generate power, will depend mainly on inverters to interface with the utility grid leading to the increase of the harmonic distortion [3],[6]. 


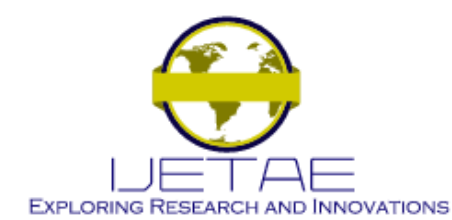

\section{International Journal of Emerging Technology and Advanced Engineering Website: www.ijetae.com (ISSN 2250-2459, Volume 2, Issue 9, September 2012)}

Besides this, the extensive use of FACT controllers to control the flow of power in transmission line has the ability of boosting the harmonic distortion levels due to the inherent non-linearity associated with these devices and the normal proliferation of using non-linear and electronically switched loads at customer side will continue to increase affect of harmonics. [2], [3].

\section{Voltage Fluctuation and Flicker}

Voltage fluctuations are changes or swings of the voltage envelope in a systematic manner or a series of random voltage variations and are always referred to as voltage flicker. In addition to its effect on light, it is responsible for reduced life of electronic, incandescent, fluorescent and cathode ray tubes, malfunction of phase locked-loops PLLs, mis-operation of electronic controllers and protection devices. Even under deregulation, voltage fluctuations and flicker will increase due to use of nonlinear and vulnerable devices, and in such environment, the control of the voltage fluctuation should be the responsibility of the Transmission utilities (Transco.) and Distribution Companies (Disco.) such as switch-mode power supplies, television sets, light dimmers, and adjustable-speed drives can also inject provided that industrial customers, especially those utilizing large arc furnaces, control the amount of fluctuation of their load current. [6].

\section{IMPACT ON ECONOMY}

\section{A. Cost of Poor Power Quality}

The impacts of poor power quality on organization's operational efficiency are significant and disruptive. It is also being evermore clearly understood that financial impacts, where relevant, are far greater than had previously been recognized. The economic impacts of power quality are usually divided into three broad categories [3]:

\section{i) Direct economic impacts:}

Production loss, unrecoverable downtime and resources (e.g. raw material, labour, capital), process restart costs, spoilage of (semi-)finished production, equipment damage, direct costs associated with the human health and safety, financial penalties incurred through non-fulfilment of contract, environmental financial penalties, utility costs associated with the interruption.

\section{ii) Indirect economic impacts:}

The cost to an organization of revenue/income being postponed, the financial cost of loss of market share, the cost of restoring brand equity.

iii) Social economic impacts:

Uncomfortable building temperatures as related to reduction in efficient working/health and safety, Personal injury or fear, also as related to reduction in efficiency and health and safety, Evacuating neighbouring residential buildings as an indirect social impact in the event of failure of industrial safety, as it relates to the additional costs incurred by an organization that has to carry out these measures.

PQ costs are usually reported in the categories of Voltage dips and swells, Short interruptions, Long interruptions, Harmonics, Surges and transients, and lastly in the category of Flicker, unbalance, earthing and electromagnetic compatibility (EMC) problems.

\section{B. Impacts of Poor Power Quality on Global Environment}

It is very difficult to assess the impact of poor PQ globally, due to non availability of up-to-date global data and also due to non performance of such assessment or study in most of the countries or regions. However the impacts are experienced by all.

A joint study by the manufacturers association of information technology (MAIT), USA and emersion network power (India) has thrown up the finding that network power downtime costs Indian economy more than $\$ 9.60$ billion annually [8]. The findings of the study have turned out to be a real eye-opener for Indian industries. While the study has taken account only direct losses suffered due to power disruption, the real figure could be much higher if indirect impacts are considered. Economic Cost of Outages of Bangladesh amounted to $1.72 \%$ (US \$778millions) of the Country GDP in 2001 [9]. Industrial losses due to poor PQ has been estimated as $\$ 150-\$ 200$ billion dollars (USD) for European Union (2001). A recent study by IBM showed that power quality problems costs U.S. businesses more than $\$ 15$ billion a year. That's an average of $\$ 79,000$ for each company [9].

To get an idea of significance of monitoring and mitigation of electricity supply needed to solve the staggering economic losses, it is essential to have the information of electricity consumption in a region. 


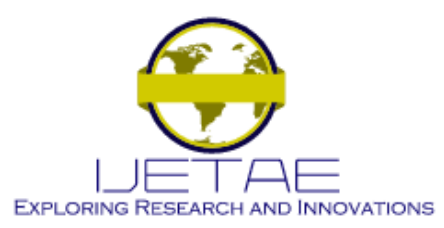

\section{International Journal of Emerging Technology and Advanced Engineering Website: www.ijetae.com (ISSN 2250-2459, Volume 2, Issue 9, September 2012)}

Fig 2 shows a plot of Indian energy consumption projections for the period 2001-2025[10].

Indian Energy consumption projections (Billion $\mathrm{KWHr}$ )

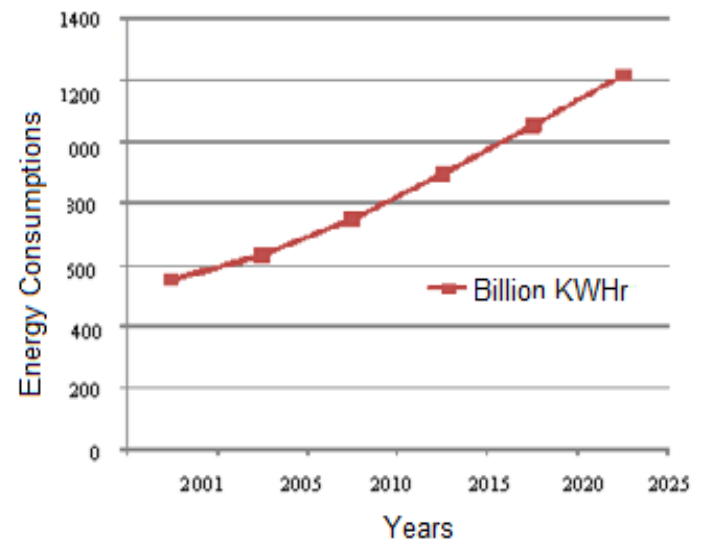

Fig.1 Indian Energy Consumption Projections in Billion KWHr.

It has been observed that there will be steep rise in the consumption of energy in India. India has got the third highest average annual percentage change (3.3\%) in energy consumption in the world [10].

\section{Downtime Impact}

Downtime causes millions of dollars in damage annually to computer networks around the Globe. Power-related issues are frequently the cause of time outs, unexplained downtime, and other commonplace system or networking glitches. Two major studies of power quality have been completed in recent years by Bell Labs and IBM [11]. Both found the areas mentioned in the table 3 to be accounted for most power-related issues: Both studies strikingly show similar results. The blackouts and large surges only makeup a small percentage of power quality problems. On the other hand, 80-90 percentages are caused by low voltage surges that causes networking problems. Thus around 80 to 90 percent of the time, electronic equipment is being affected by tiny surges as opposed to lightening flashes or blackouts. To make matters worse, these little spikes wreak havoc in terms of logic confusion, system errors, and frozen screens.

The term "sustained interruption" or "outage" describes a situation in a commercial utility system where automatic protective devices, because of the nature of the fault, cannot bring power back online, and manual intervention is required. (IEEE Standard 100-1992) [7]. Not able outages/blackouts give an idea of disruptive impacts a nd huge economic losses which were discussed in [9], [12].
The global downtime impact of poor PQ and its disruptions are shown in the following table I and II.

It has been observed that $60 \%$ of firms face power disruption

TABLE I

COST OF VOLTAGE DIPS (COUNTRY)

\begin{tabular}{|l|l|l|}
\hline \multicolumn{3}{|l|}{ Cost of voltage dips } \\
\hline Industry & Duration & Cost/sag \\
\hline U.K. steelworks & $\begin{array}{l}30 \% \text { for } \\
3.5 \text { cycles }\end{array}$ & $\$ 457447$ \\
\hline US glass plant & Less than $1 \mathrm{~s}$ & $\$ 200$ \\
\hline US petrochemicals & $2 \mathrm{~s}$ & $\$ 600$ \\
\hline US & $\begin{array}{l}\text { Annual } \\
\text { exposure }\end{array}$ & $\$ 10 \mathrm{~m}$ \\
\hline South Africa & $\begin{array}{l}\text { Annual } \\
\text { exposure }\end{array}$ & $\$ 3 \mathrm{bn}$ \\
\hline
\end{tabular}

more than once a month [9],[13]. Table I shows cost of voltage dips (country-wise) and Table II shows cost of voltage dips (industry-wise).

One study[12],[14] carried out by a major generator, measured voltage disturbances at 12 sites with demand between 5 and 30 MVA. In a 10 month period 858 disturbances were logged with a financial loss totalling $\$ 1.10 \mathrm{~m}$. The table 6 gives some typical values. It is evident that industries or plants making high value added products and those requiring multistage manufacturing processes, such as semiconductors, would face much higher losses.

TABLE II

COST OF VOLTAGE DIPS (INDUSTRY)/FINANCIAL LOSS

\begin{tabular}{|l|l|}
\hline \multicolumn{2}{|c|}{ Cost of voltage dips } \\
\hline Industry/sector & $\begin{array}{l}\text { Typical financial } \\
\text { loss per event }(\$ 000)\end{array}$ \\
\hline Semiconductor production & 5579 \\
\hline Financial trading & 8820 per hour \\
\hline Computer center & 1103 \\
\hline Telecommunications & 45 per minute \\
\hline Steel works & 515 \\
\hline Glass manufacture & 368 \\
\hline Offshore platforms & $375-1100$ per day \\
\hline Dredging/and reclamation & $75-400$ per day \\
\hline
\end{tabular}

In relation to public services like hotels and retail sectors, the PQ impact is measured in terms of slowing down their business activities, in terms of revenues that are irrevocably lost.

In addition to economical loss due to production stops, there exists an extra KWH loss due to harmonic pollution in typical network components such as transformers, cables and motors. 


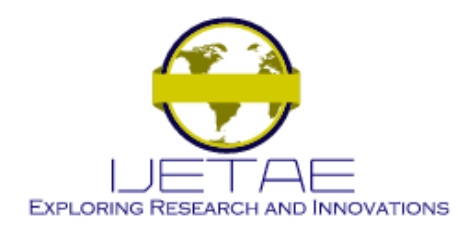

\section{International Journal of Emerging Technology and Advanced Engineering Website: www.ijetae.com (ISSN 2250-2459, Volume 2, Issue 9, September 2012)}

From the surveys, it was observed that the cost per voltage dip event was very high and single short interruptions on average are 3.3 times more costly for industry and just over 9 times more costly for services; The average cost of long interruptions is $\$ 133,800$ and is more homogenous across whole survey sample. The generic cost per event for surges and transients for this survey ranges from $\$ 176,400$ to $\$ 264,600$.[3,10]

In addition to economical loss due to production stops, there exists an extra KWH loss due to harmonic pollution in typical network components such as transformers, cables and motors. As this loss has to be supplied by the utility power plants, a financial loss and $\mathrm{CO}_{2}$ emissions can be assigned to it. Amount of loss due to this attains figures like few thousand dollars per year easily. This corresponds to a few tens of $\mathrm{CO}_{2}$ emissions/year. Hence running cost of such installations can be significant. European PQ survey is an eye opener for the whole world and authorities felt the need of regular PQ survey for their own system and to reconsider their power contingency.

European PQ survey is an eye opener for the whole world and authorities felt the need of regular PQ survey for their own system and to reconsider their power contingency measures and adopt proper mitigation. Blackouts in New York and Europe have prompted the authorities to reconsider their power contingency measures.

\section{Impacts in India}

Power scenario in India seems to be worsening. A study by IT industry body, the Manufacturers Association of Information Technology(MAIT) and US-based power distribution solution provider Emerson Network Power, India showed that India Inc lost $\$ 4.80$ billion in 2003 , and $\$ 9.60$ billion in $2008-09$, in direct losses, due to poor power quality and operating environment related downtime.[7], [8], [15]. The revenue loss due to power failure grew at an average of $11.9 \%$ in the past five years. Major reasons for downtime are power cuts (scheduled and unscheduled) due to stress on infrastructure and poor quality of power and the major impact of downtime is loss of work in progress and employee productivity. According to the study, power disruption frequency was highest in Delhi followed by Pune and Bangalore, while the average downtime cost was $\$ 1210 \mathrm{per} / \mathrm{hr}$. This trend will continue due to the lessons from global power failures encountered in western countries. Firms will need to pay more attention to maximising uptime to remain competitive in a globally networked economy.
For electricity consumers in India, supply interruptions and low voltage levels are a constant source of concern and utilities are making major investments to improve power quality. Government and regulatory commissions in India use IEEE developed reliable indices such as CAIDI, SAIDI, and SAIFI. However their use is still in an initial phase in India. For the first time in India [8], ESMI captured supply interruptions data as well as voltage levels at the ordinary consumer location at Pune.

A weekly supply interruptions recorded in Pune in 2007 is shown in the pie diagram (fig. 2). The Pie-chart shows the weekly voltage profile, i.e. $\%$ of time the voltage (V) was in a particular range. The results might look startling for PQ experts who are working in European or North American Standards for monitoring. The rated voltage was supplied only $23 \%$ of the time. The voltage was low $69 \%$ of the time. The voltage was very low $7 \%$ of the time and there was no supply at all $1 \%$ of the time, which means that there were outages for one hour and forty minutes during that week. According to the annual report of the Ministry of Power, India, losses of State Electricity Boards were \$4.3billion (in 2000) and \$ 6 billion (in 2005). Losses in the supply of electricity are $40 \%$ of production.

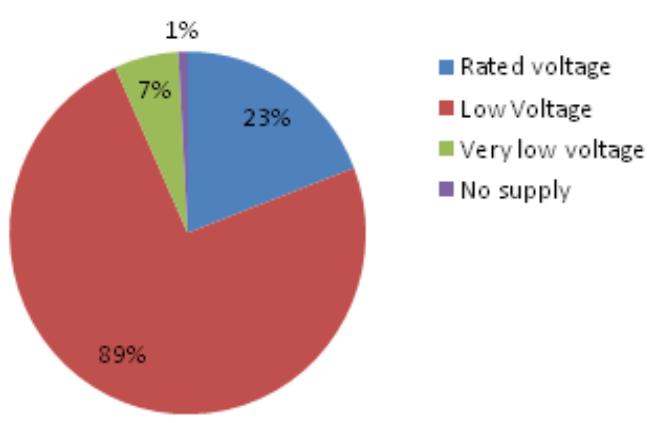

Fig.2. Weekly Voltage Profile, Prayas, (India)

Losses for the economy due to poor electricity and transport are $2 \%$ of the GDP per year [15],[16].

\section{SMART GRID ENVIRONMENTS AND PQ}

An adequate power quality guarantees the necessary compatibility between all equipments connected to the grid. It is therefore an important issue for the successful and efficient operation of existing as well as future grids. 


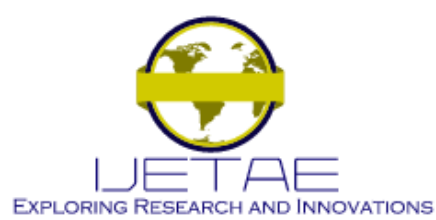

\section{International Journal of Emerging Technology and Advanced Engineering Website: www.ijetae.com (ISSN 2250-2459, Volume 2, Issue 9, September 2012)}

Due to large gap between generation and load, inefficient generating stations, overloading of system components, higher losses in the system, lack of reactive power support and regulation services, poorly planned distribution network, low metering efficiency and bill collection and power theft- smart grid is essentially required. The power quality issues are very important and play the most significant role for the development of smart grids. The "smart" properties of future grids would be a challenge for new approaches in an efficient management of power quality. Especially the advanced communication technologies can establish new ways for selective power quality management.

Smart grid is a vision. A more reliable, secure, economical, efficient, environmentally friendly, and more safer grid is the vision in the name of the smart grid.[3]. In such vision, monitoring of power quality is the real challenge. The present methods or systems of monitoring are not capable to cope with the intelligent smart grid system. An intelligent power quality monitoring system is an essential requirement of the smart grid. The PQM should be capable to detect most (and almost all) of the power quality events and disturbances smartly. Intelligent PQM is the need for smart grid due to principal functionality characteristics of Smart Grids, which includes: i) active participation by consumers, ii) accommodation of all generation and storage options, iii) enabling new products, services, and markets, iv) providing power quality (PQ) for the digital economy, v) optimizing asset utilization and to operate efficiently, vi) to anticipate and respond to system disturbances (self-heal), and vii) to operate resiliently against attack and natural disaster (cyber security). [3], [16], [17], [18].

The smart grid of the future should include:

i) Network monitoring to improve reliability,

ii) Equipment monitoring to improve maintenance,

iii) Product (power) monitoring to improve PQ.

In order to achieve these goals, the actual distribution system infrastructure (especially meters and remotely controlled IEDs) should be used to gather as much information as possible related to network, equipment and product (i.e. power quality and reliability) to improve the distribution system overall performance.

In all these aspects, a smart PQ monitoring is an essential requirement. This will be an instrumental to make the smart grid perform efficiently, reliably with proper realtime monitoring and corresponding automatic mitigation and other required follow-up actions.
Then only this smart grid vision will become a reality leading to the fulfilling of the power demand of the present and future world.

\section{CONCLUSIONS}

The cost of poor PQ is high and rising. Utility deregulation effects on power quality requiring industrywide action to maintain sufficient standards. The paper gives insights on global economical losses due to poor PQ. The business risk posed by PQ problems is a real one with even 'low tech' industries exposed to serious financial losses.

Smart grid is the most important vision for future power system. Existing PQM methods are generally one way communication system and should be replaced by methods with smart grid sensors for smart metering with advanced metering infrastructure (AMI) in distribution system (twoway communication ).

Intelligent and efficient PQ monitoring will provide the information needed to validate compliance, improve system stability, and eliminate unplanned downtime. Smart grid needs intelligent PQ monitoring system to make the smart grid perform efficiently, reliably with proper real-time monitoring and corresponding automatic mitigation and other required follow-up actions.

\section{REFERENCES}

[1] Math H.J.Bollen, "Understanding Power Quality Problems", IEEE Press Series on Power Engineering, 2000, pp. 6-124.

[2] E.F. Fuchs and Mohammad A.S. Masoum, "Power Quality in Power Systems and Electrical Machines", Academic Press, 2008.

[3] S.H. Laskar, Mohibullah, "Power Quality Monitoring by Software Development”, Int. Conf. on Power System Engg, (ICPSE2010), Feb 24-26, 2010, Penang, Malaysia.

[4] Task force 38.06.01. Methods to consider customer interruption costs in power system analysis. Technical report, CIGRE, 2001.

[5] L. Tomesc, R. Duma, M. Abrudean, P. Dobra "Low cost embedded solution for measuring power quality parameters", Proc. $17^{\text {th }}$ World Congress, Int. fed. Auto. Cont., Seoul, July 6-11, 2008.pp.12971-76.

[6] W.L. Tse and 1W.L. Chan,“A Low Cost Web-based Supply Voltage Quality Monitoring System" Pakistan Journal of Information and Technology 2 (3): 256-264, 2003.

[7] J. Arrillaga, M. H. J. Bollen and N.R.Watson, "Power Quality Following Deregulation", Proc. IEEE, vol.88, pp.246-251, 2000.

[8] IEEE Recommended Practice for Monitoring Electric Power Quality, 1159-2009

[9] Electricity Supply Monitoring Initiative, ESMI, Prayas ,India, 2009. http://www.prayaspune.org/peg

[10] Power quality in European Electricity Supply Networks, $1^{\text {st }}$ edition. Technical report, Euroelectric, 200 


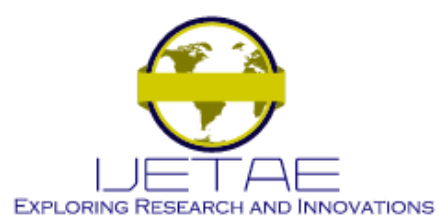

\section{International Journal of Emerging Technology and Advanced Engineering}

\section{Website: www.ijetae.com (ISSN 2250-2459, Volume 2, Issue 9, September 2012)}

[11] Projections of Energy Information Administration (EIA), System for the Analysis of Global Energy Markets (2004).

[12] Bell lab report on "PQ Issues Cause Computer Problems".

[13] http://en.wikipedia.org/wiki/List_of_power_outages

[14] Roman Targosz, J. Manson, "Pan-European Power Quality SurveyA study of the impact of power quality on electrical energy critical industrial sectors" $9^{\text {th }}$ Int. conf. on Elect. Power Quality and Utilization (Oct'2007), IEEE Xplore.

[15] Mark McGranaghan, "Economic Evaluation of Power Quality", IEEE Power Engg. review, Vol.22, issue 2, pages 8-12, Feb. 2002
[16] Ministry of Power, India report; http://www.powermin.nic.in

[17] The smart grid - an introduction, (US) Department of Energy, 2008; www.oe.energy.gov/SmartGridIntroduction.htm.

[18] S.H. Laskar, Sanaullah and Mohibullah, "Power quality monitoring in sustainable energy systems", published in the proc. of IEEE Int. Symp. on Sustainable Systems and Tech.(ISSST 2012), held at Boston, 16-18 May'2012. D.O.I.:10.1109/ISSST2012.6228002; Page 1-6. 